
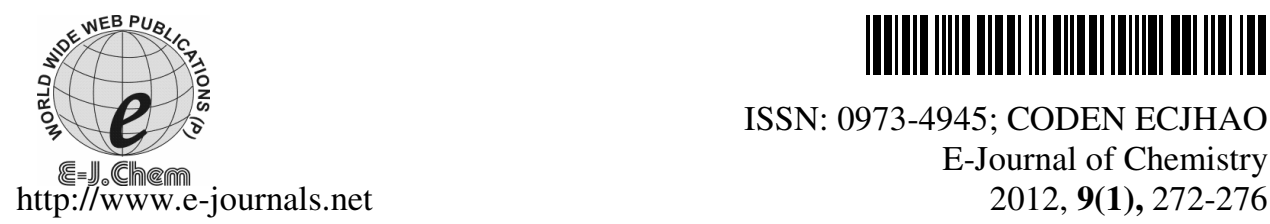

ISSN: 0973-4945; CODEN ECJHAO

E-Journal of Chemistry

2012, 9(1), 272-276

\title{
Comparison of Catalysts Preyssler and Silica-Supported Nano Preyssler in the Synthesis of Acetyl Salicylic Acid
}

\author{
H. NAZARI ${ }^{\S *}$, A. AHMADPOUR ${ }^{\S}$, F. F. BAMOHARRAM ${ }^{\#}$, \\ M. M. HERAVI and N. ESLAMI ${ }^{\S}$ \\ ${ }^{\S}$ Department of Chemical Engineering \\ Ferdowsi University of Mashhad, Iran \\ \#Department of Chemistry, School of Sciences \\ Islamic Azad University - Mashhad Branch, Mashhad, Iran \\ Department of Chemistry \\ School of Sciences, Alzahra University, Tehran, Iran \\ hdsh_nazari@yahoo.com
}

Received 17 April 2011; Accepted 3 July 2011

\begin{abstract}
The extensive demand for cleaner environment is forcing chemical industry to use less hazardous materials. In this regard, heteropolyacids attracted considerable amount of interest due to the less toxic behavior in addition of possessing higher acidity. Heteropoly acids have been used as catalysts for the reaction of salicylic acid with acetic anhydride. The performance of different forms of heteropoly acids in the presence of acetic anhydride as acetylating agent for acetylation of salicylic acid was compared. The best conditions were observed using Preyssler and Silica-supported Preyssler Nanoparticles as catalysts. The catalyst is recyclable and reusable.
\end{abstract}

Keywords: Heteropolyacid, Acetylsalicylic acid, Silica-supported Preyssler Nanoparticles, Catalyst.

\section{Introduction}

The drive to develop green processes has led to the development of solid acid catalysts to a significant increase in research activities both in academic and industrial sections. These materials can replace the corrosive liquid acids currently used in many industries. A variety of materials have been used as solid acid catalysts such as clays, zeolites, sulfated metal oxides, heteropoly acids (HPAs), etc. Each of these materials offers unique properties that can influence the catalytic activity. Among these solid acids, heteropoly acids have unique properties such as strong Brønsted acidity, structure alterability, high proton mobility and environmental friendliness. They show very strong Brønsted acidity values, approaching the 
super acid region. Due to their stronger acidity, they generally exhibit higher catalytic activities than conventional catalysts, such as mineral acids, ion-exchange resins, zeolites, etc. They are widely used in both heterogeneous and homogeneous systems ${ }^{1-5}$.

Heteropoly acids, presently being used in several industrial processes, are important for the so-called clean technologies since many of the environmental pollution and corrosion problems of the traditional technologies are avoided ${ }^{1,2,6}$.

Among the HPAs, Preyssler catalyst is green with respect to corrosiveness, safety, quantity of waste, and separability. This heteropoly acid with fourteen acidic protons is an efficient solid "supper acid" catalyst with unique hydrolytic stability $(\mathrm{pH}=0-12)^{7,8}$.

Over the last decade, due to the unique properties of nanoparticles along with their novel properties and potential applications in different fields, synthesis and characterization of catalysts with lower dimensions have became the most interesting topic of research ${ }^{9}$. As the particle size decreases, the relative number of surface atoms and hence the activity increases. Moreover, due to quantum size effects, nanometer-sized particles may exhibit unique properties for a wide range of applications ${ }^{10}$.

Recently, most considerations raised the interest for synthesis of Keggin nano catalysts $^{11}$, but the synthesis and catalytic activity of Preyssler nano-catalyst has been largely overlooked. In our attempt to use HPAs as catalysts in organic reactions, we reported that Preyssler type of HPAs, $\mathrm{H}_{14}\left[\mathrm{NaP}_{5} \mathrm{~W}_{30} \mathrm{O}_{110}\right]$, shows strong catalytic characterization ${ }^{12}$. The exceptional properties of nano particles encouraged us to immobilize $\mathrm{H}_{14}\left[\mathrm{NaP}_{5} \mathrm{~W}_{30} \mathrm{O}_{110}\right]$ into the $\mathrm{SiO}_{2}$ nano particles and investigate the catalytic behavior of this new catalyst.

Organic esters represent an important class of intermediates widely used in fine chemicals, drugs, plasticizers, food preservatives, pharmaceuticals, solvents, perfumes, cosmetics and chiral auxiliaries ${ }^{13}$. Acetyl salicylic acid is commonly known by its trade name aspirin. Aspirin is a registered trademark of Bayer AG in Germany and more than 80 other countries. Aspirin is an effective non-steroidal analgesic, antipyretic and anti-inflammatory drug and is one of the most widly used medicine around the world ${ }^{14-18}$.

The synthesis of aspirin is classified as an esterification reaction. Salicylic acid is treated with acetic anhydride, an acid derivative, causing a chemical reaction that turns salicylic acid's hydroxyl group into an acetyl group. Small amounts of sulfuric acid (and occasionally phosphoric acid) are almost always used as a catalyst. This method is commonly employed in undergraduate teaching labs ${ }^{19,20}$. Both acids are strongly corrosive and must be handled with care. In the present study, esterification of salicylic acid with acetic anhydride was carried out with Preyssler and Silica-Suported NanoPreyssler.

\section{Experimental}

Acetic anhydride, salicylic acid, sodium tungstate dihydrate, potassium chloride, orthophosphoric acid, sulfuric acid and other chemicals were obtained from Merck Company and used as received.

\section{Catalyst preparation}

Potassium salt of Preyssler's anion was prepared according to the procedure developed in our laboratory ${ }^{7}$. Preyssler HPAs, $\mathrm{H}_{14} \_\mathrm{P}_{5}$, was prepared as follows: $33 \mathrm{~g} \mathrm{Na}_{2} \mathrm{WO}_{4 \cdot 2} \mathrm{H}_{2} \mathrm{O}$ were dissolved in $45 \mathrm{~mL}$ of water and mixed at $45{ }^{\circ} \mathrm{C}$ for $30 \mathrm{~min}$. Then, this solution was cooled to room temperature, and $25 \mathrm{~mL}$ of concentrated phosphoric acid was added. The resulting yellow solution was refluxed for $5 \mathrm{~h}$. The solution was brought to room temperature, diluted with water and then during stirring, $10 \mathrm{~g}$ of $\mathrm{KCl}$ was added. The mixture was stirred and then heated up to dryness. The product was dissolved in warm water and upon cooling to room 
temperature white crystals was formed. The free acid was prepared by passage of a solution of the potassium salt in water through a column of resin and evaporation of the elute to dryness under vacuum ${ }^{7}$.

Silica-supported Preyssler nano particles were prepared according to our previous work $^{21}$. For synthesis of supported catalyst, a solution of surfactant in cyclohexane (0.2 M) was added to a solution of Preyssler acid in a specified amount of water. The molar ratio of water to surfactant was selected as 3,5 and 7. Then, tetraethoxysilan was added into the microemulsion phase. After mixing for various times $(8,12,18,25$ and $30 \mathrm{~h})$ at room temperature, dispersed Preyssler acid $/ \mathrm{SiO}_{2}$ nano structures were centrifuged $(1500 \mathrm{rpm})$ and the particles were rinsed with acetone ( 4 times) and dried in a vacuum oven. The optimum ratio of water to surfactant was 3:1 and the optimum time ${ }^{21}$ was $30 \mathrm{~h}$. Although micro emulsion procedure has been used by some authors, this method has never been reported for the synthesis of Preyssler nanostructures with different morphologies.

\section{General procedure for aspirin synthesis}

The homogeneous process was performed by adding acetic anhydride $(5 \mathrm{~mL})$ to a solution of Preyssler ( $0.2 \mathrm{~g}$ ) and salicylic acid ( $\mathrm{g}$ ) at room temperature with stirring. At the end of reaction, the mixture was diluted with $50 \mathrm{~mL}$ of water and the crude product was precipitated in an ice bath. The crude product was removed and after the usual work up, the resulting solid was washed with cold water and recrystallized in ethanol. The product was characterized by comparison of its spectroscopic IR data and melting point with that of an authentic sample. The product yield was determined quantitatively.

\section{Catalyst recycling}

At the end of the reaction, the catalyst was recovered by water and re-used in the same reaction. The recycled catalyst was used without observation of appreciable lost in its catalytic activity.

\section{Results and Discussion}

Silica-supported Preyssler nanostructures were obtained through a microemulsion method. The presence of heteropolyacid $\left(\mathrm{H}_{14}\left[\mathrm{NaP}_{5} \mathrm{~W}_{30} \mathrm{O}_{110}\right]\right)$ on the $\mathrm{SiO}_{2}$ nano particles was confirmed by infrared (IR) spectroscopy (Figure 1). It could therefore be confirmed that the heteropolyacid $\left(\mathrm{H}_{14}\left[\mathrm{NaP}_{5}-\mathrm{W}_{30} \mathrm{O}_{110}\right]\right)$ was successfully immobilized onto the $\mathrm{SiO}_{2}$ nano particles. IR study showed that the HPA stayed intact on the nano particles after it was recycled two times in the reaction ${ }^{21}$.

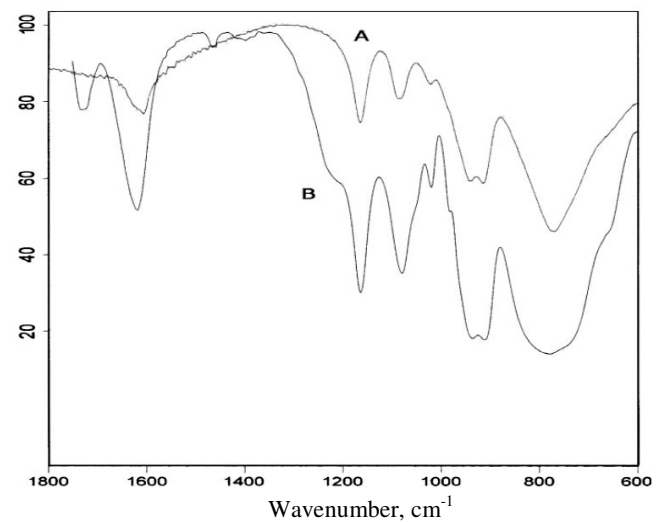

Figure 1. IR spectroscopy of Preyssler heteropolyacid in nano form (A) and bulk form (B) ${ }^{22}$ 
The results of acetylation of salicylic acid with acetic anhydride using two Preyssler form as catalysts at room temperature $\left(20^{\circ} \mathrm{C}\right)$ are shown in Table 1.

Table 1. Yields of aspirin in acetylation of salicylic acid with two different heteropolyacid catalysts at room temperature

\begin{tabular}{|c|c|c|c|}
\hline Entry & Time, min & Catalyst & Yield, \% \\
\hline 1 & 30 & $\begin{array}{c}\text { NanoPreyssler } \\
\left(\mathrm{H}_{14}\left[\mathrm{NaP}_{5} \mathrm{~W}_{30} \mathrm{O}_{110}\right] / \mathrm{SiO}_{2}\right)\end{array}$ & 72 \\
\hline 2 & 30 & Preyssler $\left(\mathrm{H}_{14}\left[\mathrm{NaP}_{5} \mathrm{~W}_{30} \mathrm{O}_{110}\right]\right)$ & 66 \\
\hline 4 & 45 & $\begin{array}{c}\text { NanoPreyssler } \\
\left(\mathrm{H}_{14}\left[\mathrm{NaP}_{5} \mathrm{~W}_{30} \mathrm{O}_{110}\right] / \mathrm{SiO}_{2}\right)\end{array}$ & 76.5 \\
\hline 5 & 45 & Preyssler $\left(\mathrm{H}_{14}\left[\mathrm{NaP}_{5} \mathrm{~W}_{30} \mathrm{O}_{110}\right]\right)$ & 71.5 \\
\hline 7 & 60 & $\begin{array}{c}\text { NanoPreyssler } \\
\left(\mathrm{H}_{14}\left[\mathrm{NaP}_{5} \mathrm{~W}_{30} \mathrm{O}_{110}\right] / \mathrm{SiO}_{2}\right)\end{array}$ & 79 \\
\hline 8 & 60 & Preyssler $\left(\mathrm{H}_{14}\left[\mathrm{NaP}_{5} \mathrm{~W}_{30} \mathrm{O}_{110}\right]\right)$ & 74.75 \\
\hline 10 & 90 & $\begin{array}{c}\text { NanoPreyssler } \\
\left(\mathrm{H}_{14}\left[\mathrm{NaP}_{5} \mathrm{~W}_{30} \mathrm{O}_{110}\right] / \mathrm{SiO}_{2}\right)\end{array}$ & 82.5 \\
\hline 11 & 90 & Preyssler $\left(\mathrm{H}_{14}\left[\mathrm{NaP}_{5} \mathrm{~W}_{30} \mathrm{O}_{110}\right]\right)$ & 75 \\
\hline 13 & 120 & $\begin{array}{c}\text { NanoPreyssler } \\
\left(\mathrm{H}_{14}\left[\mathrm{NaP}_{5} \mathrm{~W}_{30} \mathrm{O}_{110}\right] / \mathrm{SiO}_{2}\right)\end{array}$ & 85 \\
\hline 14 & 120 & Preyssler $\left(\mathrm{H}_{14}\left[\mathrm{NaP}_{5} \mathrm{~W}_{30} \mathrm{O}_{110}\right]\right)$ & 76.5 \\
\hline
\end{tabular}

The experiment was carried out for the first time by an inexpensive, recyclable Nano Preyssler's anion. The results show that Nano Preyssler has higher activity and performance in esterification reactions compared to Preyssler.

The best yield of aspirin (85\%) with $100 \%$ selectivity was attained with Nano Preyssler at almost $2 \mathrm{~h}$ of reaction at room temperature. Preyssler has also lower activity than the supported Nano Preyssler. It leads to $76.5 \%$ aspirin with $100 \%$ selectivity after $2 \mathrm{~h}$ (Entry 10).

It is clear from these reactions that the efficiency of $\left(\mathrm{H}_{14}\left[\mathrm{NaP}_{5} \mathrm{~W}_{30} \mathrm{O}_{110}\right]\right) / \mathrm{SiO}_{2}$ is higher than these of Preyssler. The reason is due to higher surface area available and also preservation of HPA structure in the silica-supported form of Preyssler. Also, as a matter of fact, if the particle size of nanomaterial decreases, the relative number of surface atoms will be increased and thus the catalyst activity will be enhanced.

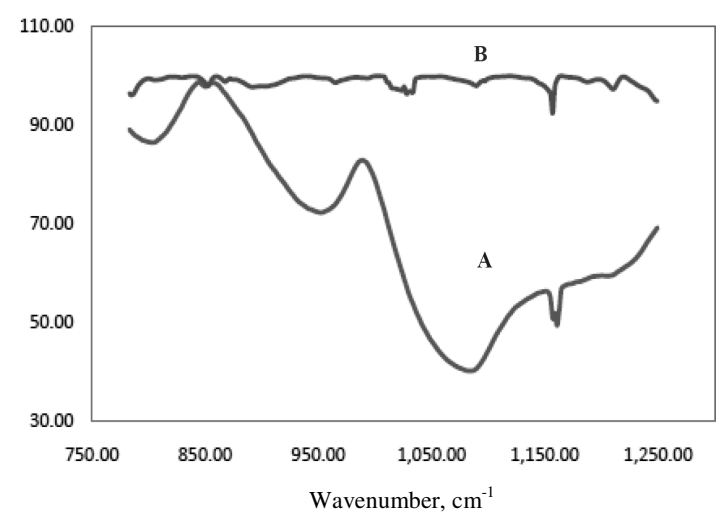

Figure 2. IR spectroscopy of recovered Preyssler heteropolyacid in nano form (A) and bulk form (B) 
The reusability of the catalyst was also investigated. At the end of the reaction, the catalyst was recovered by a simple filtration. The recycled catalyst was washed with water and subjected to a second run of the reaction process. IR spectrum of the recovered solid catalyst (Figure 2) indicated that the catalyst can be recovered without structural degradation.

\section{Conclusion}

The present study demonstrates that Preyssler is an effective solid acid catalyst for the preparation of aspirin. Among different forms of Preyssler catalysts used, $\mathrm{SiO}_{2}$ supported Nano Preyssler shows higher activity compared to the Preyssler. This method demonstrates the applicability of Preyssler's anion for those reactions that require solid catalysts with strong acidic properties. In addition, simple experimental setup and procedure makes this method a useful addition to the present methodologies.

\section{References}

1. Misono M, Chimie / Chem., 2000, 3, 471.

2. Mizuno N and Misono M, Chem Rev., 1998, 98, 199.

3. Okuhara T, Mizunob N and Misono M, Appl Catal A: General . 2001, 222, 63.

4. Kozhevnikov I V, Chem Rev., 1998, 98, 171.

5. Katsoulis D E, Chem Rev., 1998, 98, 359.

6. Romanelli G, Ruizb D, Vzqueza P, Thomasa H and Autino J C, Chem Eng J., 2009, 161,355.

7. Bamoharram F F, Heravi M M, Roshani M, Jahangir M and Gharib A, Appl Catal A: General, 2006, 302, 42.

8. Heravi M M, Bamoharram F F, Rajabzadeh G, Seifi N and Khatami, M, J Mol Catal A: Chemical, 2006, 259, 213.

9. Gorla C R, Emanetoglu N W, Liang S, Mayo W E, Lu Y, Wraback M and Shen H, $J$ Appl Phys.1999, 85, 259.

10. Zheng J, Zhang C and Dickson R M, Phys Rev Lett., 2004, 93, 7.

11. Sawant D P, Vinu A, Jacob N E, Lefebvre F and Halligudi S B, J Catal., 2005, 235, 251.

12. Heravi M M, Sadjadi S, Sadjadi S, Oskooie H A, Shoar R H and Bamoharram F F, $S$ Afr J Chem., 2009, 62, 1.

13. Aromatic Chemicals, Perfumes and Flavour Technology, SBP Board of Consultants and Engineers, SBP Chemical Engineers Series No. 54 (Small Business Publications Delhi), 1986.

14. Kraus S and Arber N, Nature Reviews Gastroenterology and Hepatology. 2010,217, 241.

15. Berg M, Søreide K, Nature Reviews Clinical Oncology. 2010, 225, 326.

16. Slattery M L, Samowitz W, Hoffman M, Ma K N, Levin T R and Neuhausen S, Cancer Epidemiol Biomarkers Prev., 2004, 13, 538.

17. Flossmann E and Rothwell P M, Lancet. 2007, 369, 1603.

18. Cryer B, Bhatt DL, Lanza F L, Dong J, Lichtenberger L M and Marathi U K, The American Journal of Gastroenterology, 2010, 106, 272.

19. Pavia D L, Lampman G M, Kriz G S, Introduction to Organic Laboratory Techniques: A Contemporary Approach; Philadelphia, 1976, 27.

20. Miller J A and Neuzil E F, Modern Experimental Organic Chemistry; Heath Lexington, MA, 1982, 192.

21. Heravi M M, Sadjadi S, Oskooie H A, Shoar R H and Bamoharram F F, $J$ Chinese Chemical Society, 2009, 56, 246.

22. Bamoharram F F and Heravi M M, Advanced Reserch in Physics and Engineering, 2010, 47. 


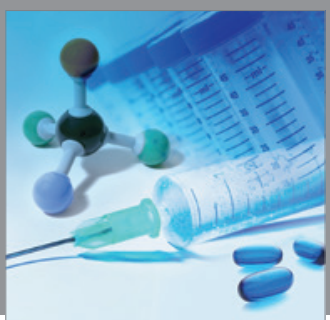

International Journal of

Medicinal Chemistry

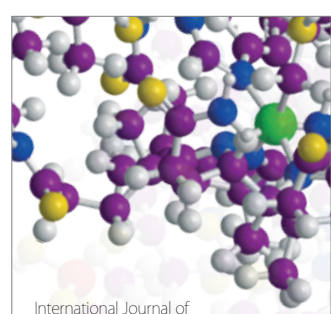

Carbohydrate Chemistry

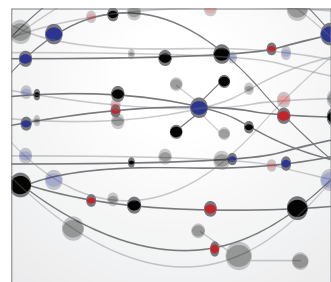

The Scientific World Journal
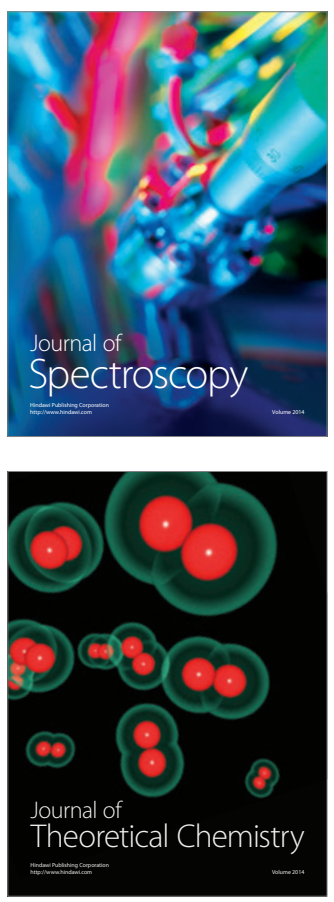
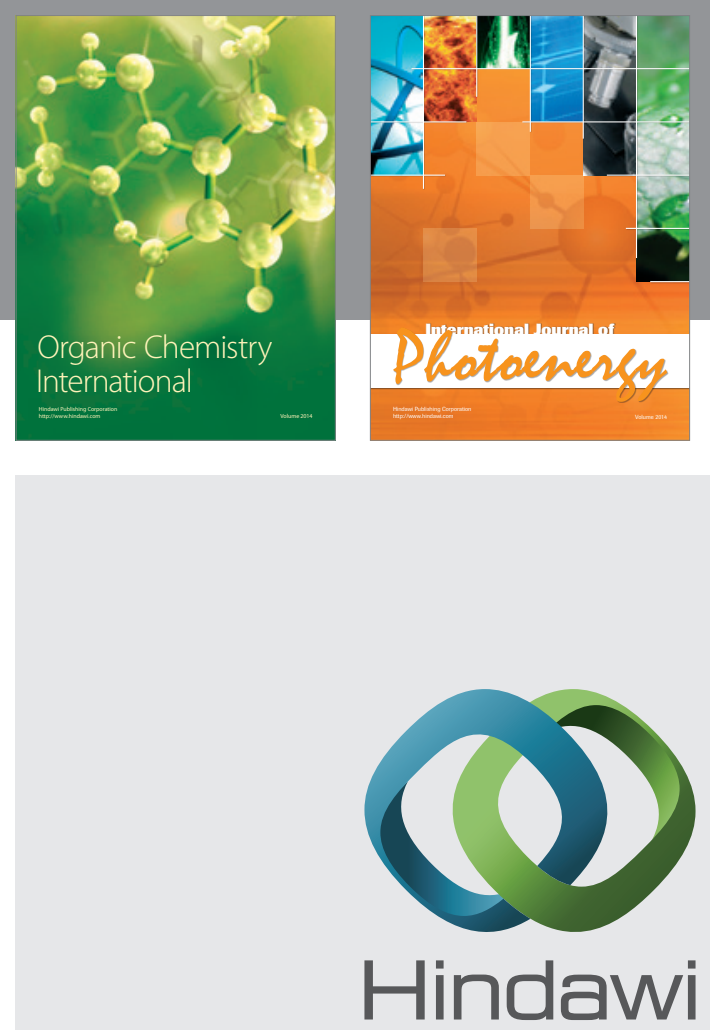

Submit your manuscripts at

http://www.hindawi.com
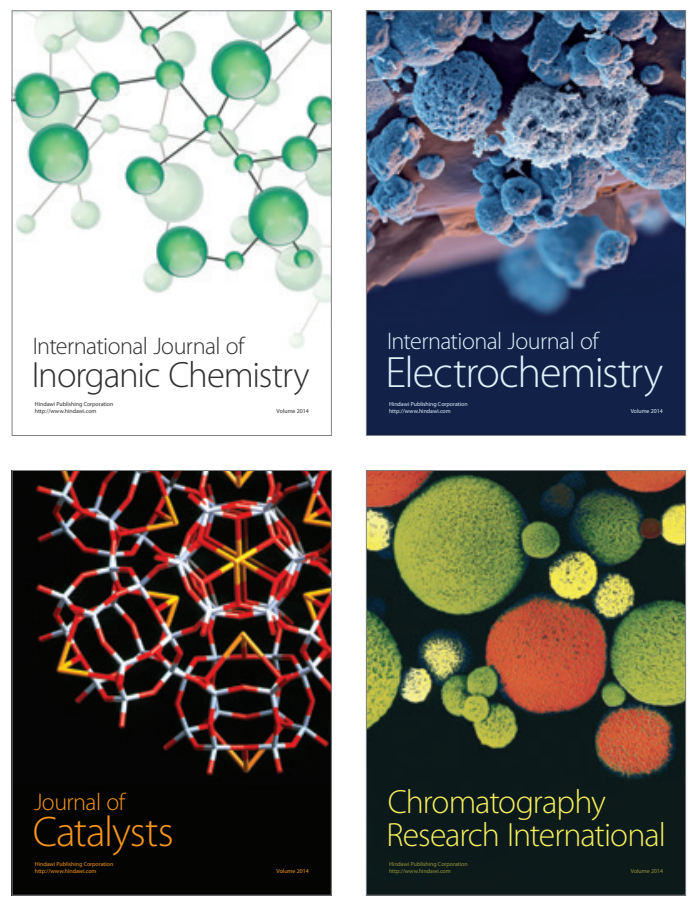
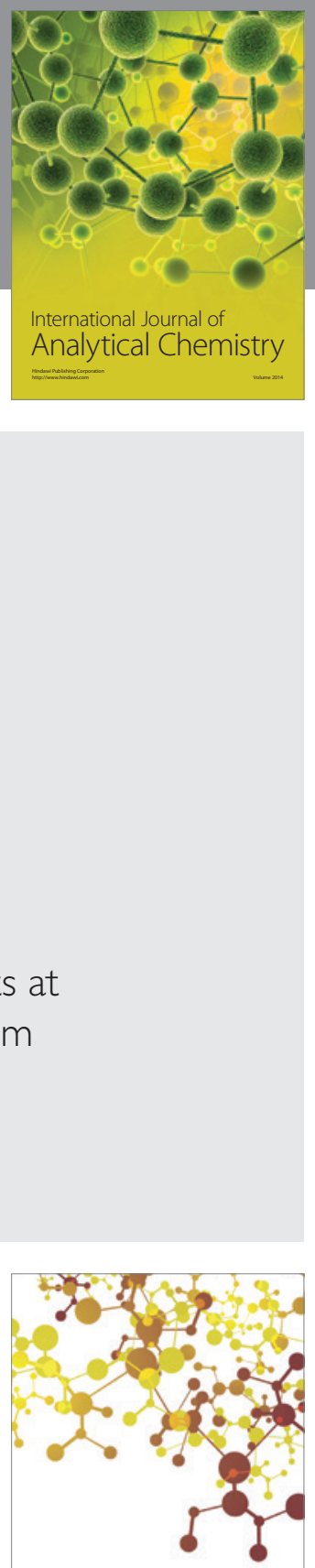

Journal of

Applied Chemistry
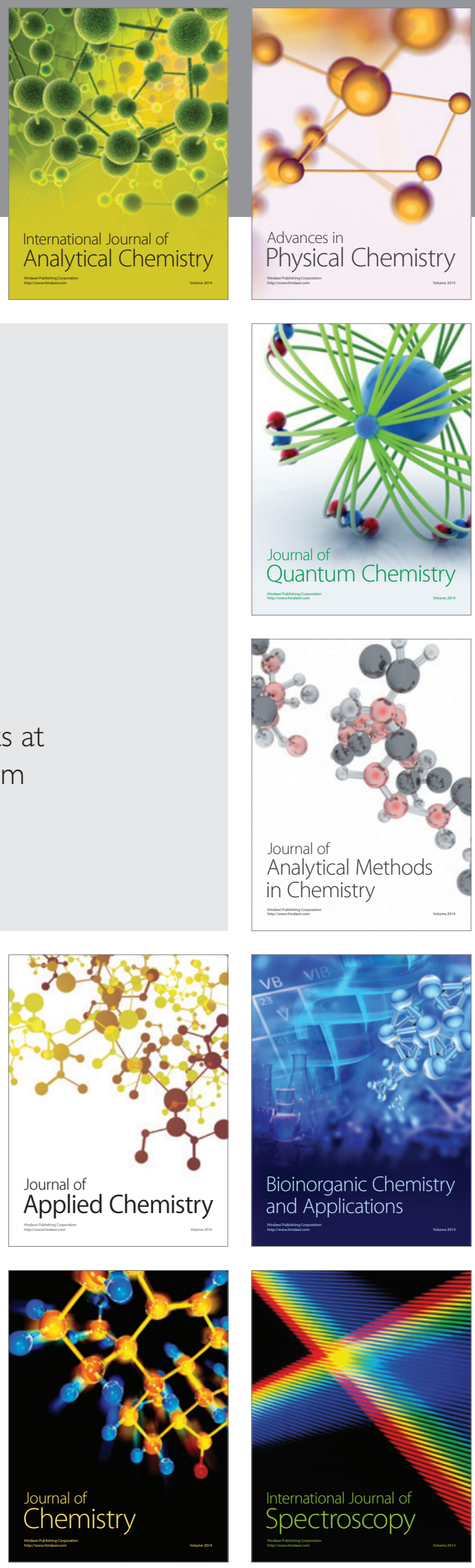